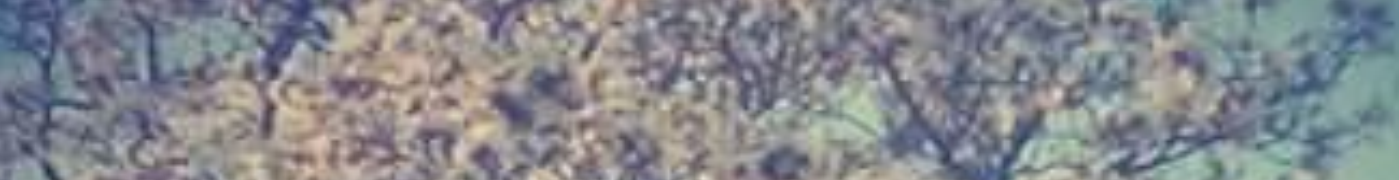

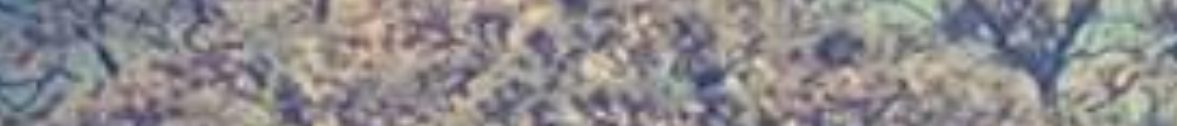

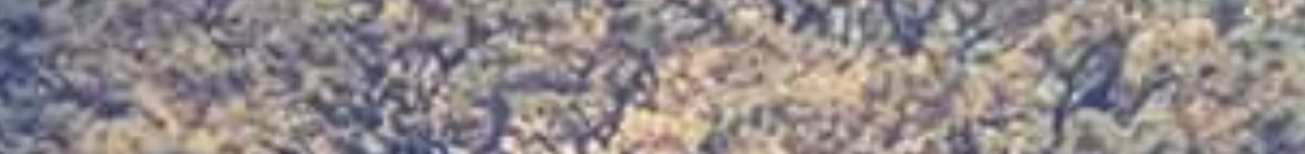

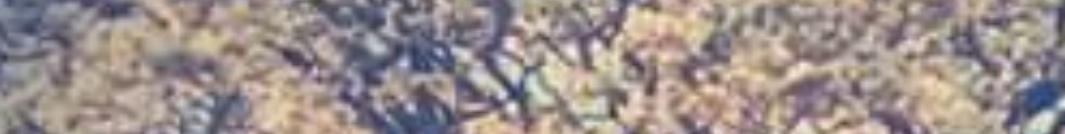

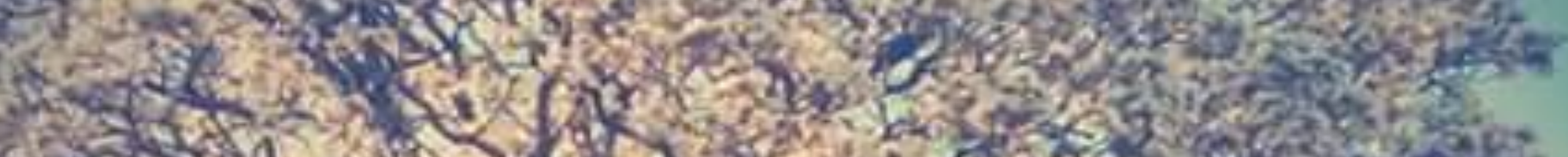
a P.

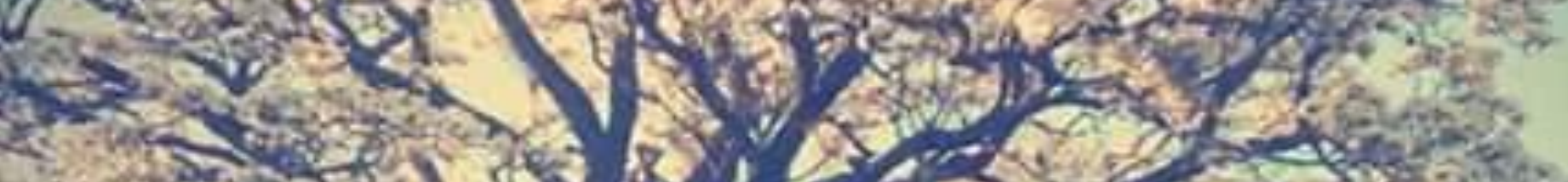

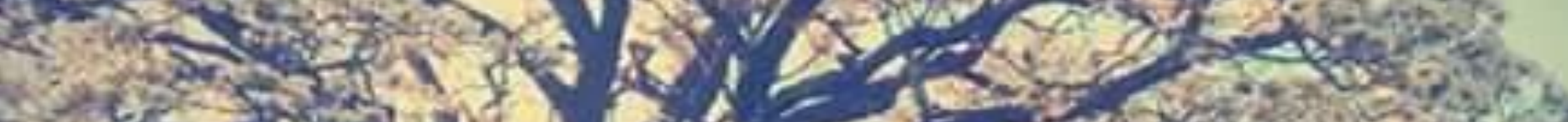

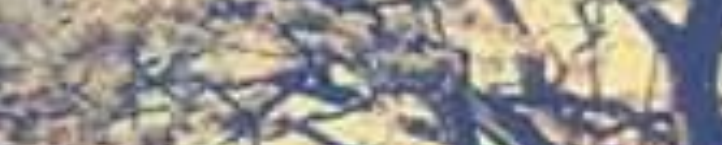
zestas

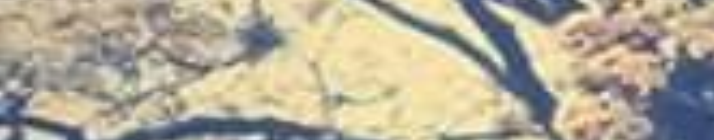

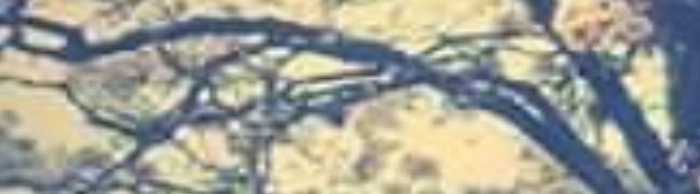

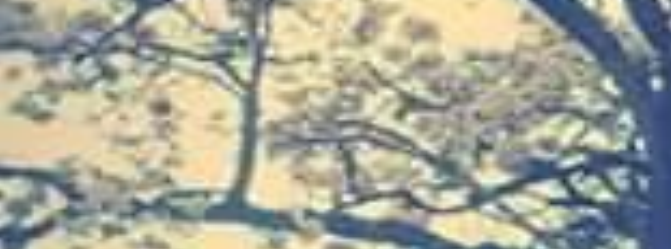

is

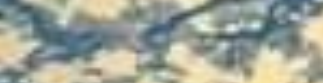

$x+\frac{1}{2} x^{2}$

at

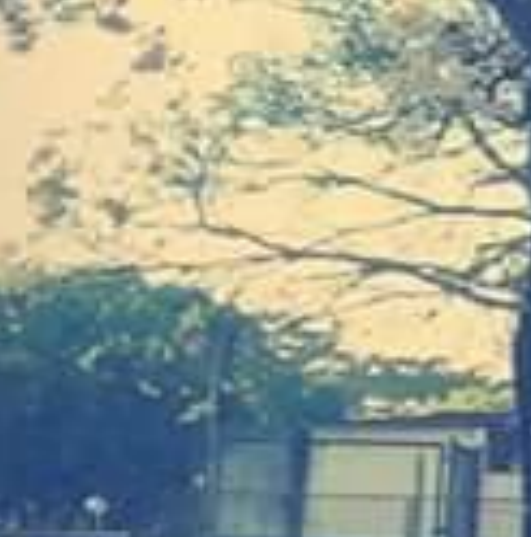

Hini

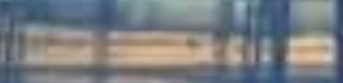

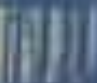

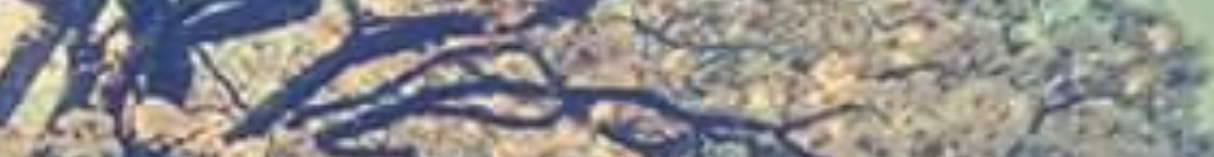
$37^{1}$.

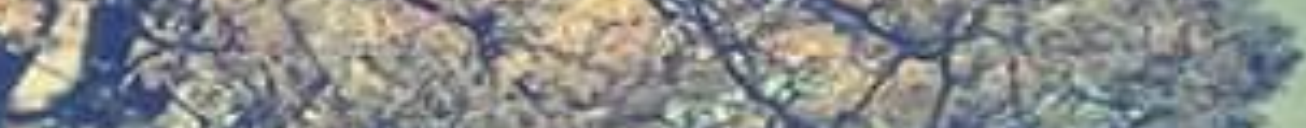

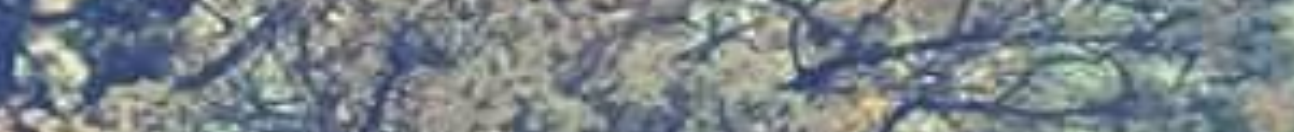

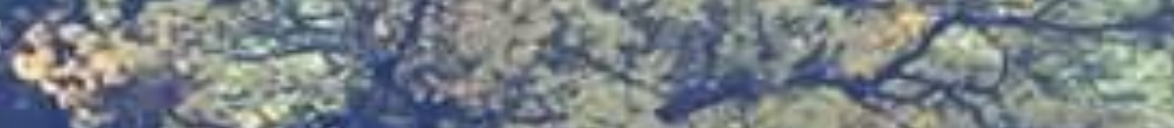

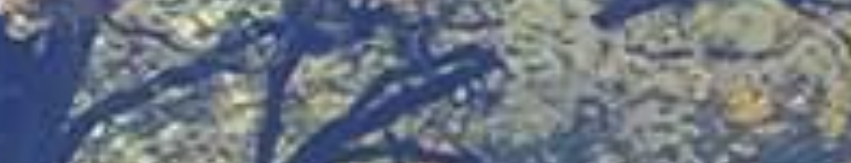

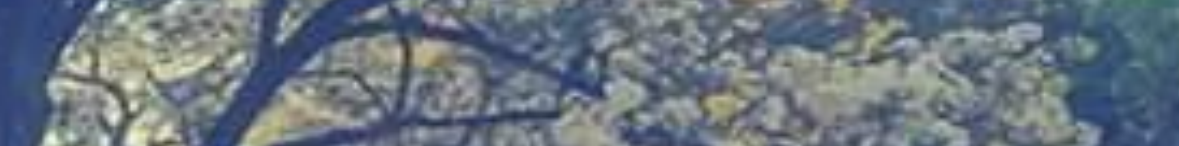

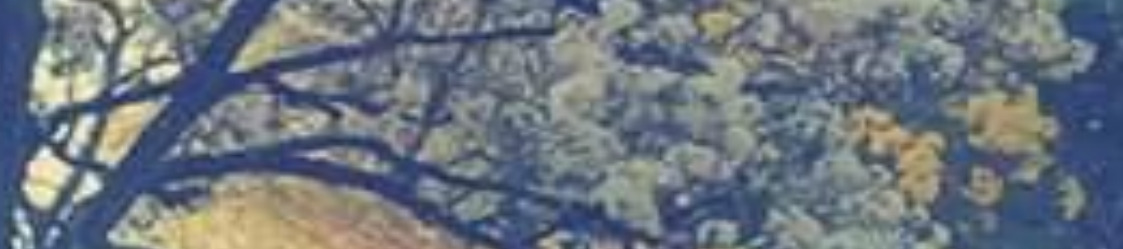
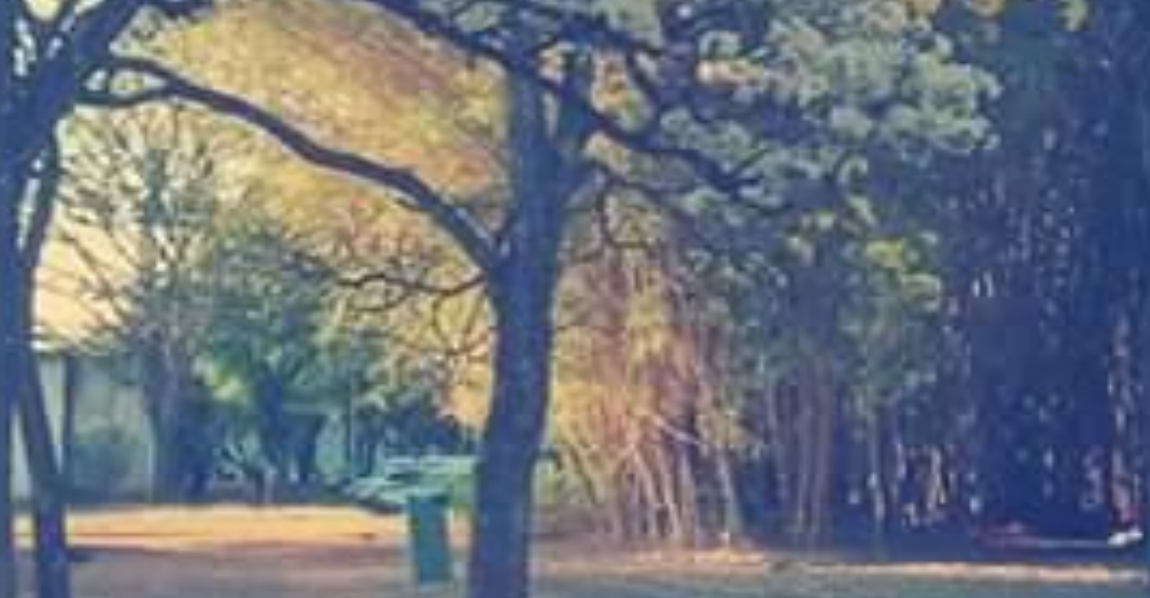

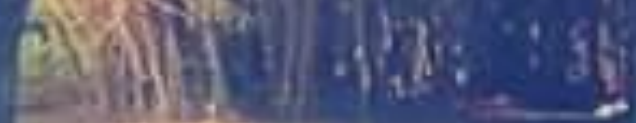




\title{
O estudo da relação Turismo, Eventos e Acolhimento para transformação da práxis numa prática refletida.
}

The study of the relation Tourism, Events and Reception for the transformation of praxis into a reflected practice.

\author{
Luciana Resende Borges ${ }^{1}$ \\ Biagio Mauricio Avena ${ }^{2}$
}

\footnotetext{
${ }^{1}$ Mestre em Turismo pelo Centro de Excelência em Turismo da Universidade de Brasília - CET / UnB. Especialista em Gestão e Planejamento de Eventos pela atual Pontifícia Universidade Católica de Goiás - PUC - GO. Graduada em Hotelaria pelo atual Instituto Federal de Goiás - IFG. Experiência profissional no Turismo, Hotelaria, Eventos e Administração. luciana rborges@yahoo.com.br

${ }^{2}$ Pós-doutor em Difusão do Conhecimento; Doutor e Mestre em Educação; Especialista em Gestão Hoteleira. Docente do IFBA e do Mestrado Profissional em Turismo do CET/UnB. bmavena@gmail.com
} 


\section{Resumo}

Turismo, Eventos e Acolhimento passam por uma evolução, teórica e prática, aliados aos saberes dos indivíduos, possuem potencialidades econômicas e sociais para a sociedade. Este trabalho propõe uma análise destes campos de investigação e expõe uma compilação de dados oriundos das pesquisas bibliográficas e de campo realizadas para a conclusão da dissertação intitulada 'O Saberfazer dos sujeitos protagonistas dos eventos como lugar de acolhimento'. Com Método Multirreferencial, pesquisa qualitativa e estudo de caso, conferiu-se a importância do sujeito como agente de acolhimento, a necessidade de qualificação, em busca da transformação da práxis numa prática refletida.

Palavras-chave: Turismo. Eventos. Acolhimento. Saber-fazer. Qualificação profissional em eventos.

\section{Abstract}

Tourism, Events and Reception go through an evolution, theoretical and practical, allied to the knowledge of individuals, have economic and social potential for society. This work proposes an analysis of these fields of investigation and presents a compilation of data from the bibliographical and field research carried out for the conclusion of the dissertation entitled 'The Know-how of the subjects protagonists of the events as place of reception'. With Multirreferencial Method, qualitative research and case study, the importance of the subject as host agent was verified, the qualification need of these actors, in search of the transformation of praxis into a reflected practice.

Keywords: Tourism. Events. Reception. know how. Professional qualification in events.

\section{Introdução}

Ao longo da trajetória histórica do turismo percebem-se transformações e evoluções seja no aspecto conceitual e acadêmico ou na conduta de suas práticas, o que influencia diretamente nos sujeitos envolvidos nos processos turísticos.

O crescimento relevante também está presente no segmento 'Turismo e Eventos', com influências econômicas e sociais, visto que é considerado como indutor e/ou criador de fluxo turístico para uma localidade.

Muitos são os esforços em abordar o turismo por âmbitos econômicos, tanto por autores quanto por órgãos relacionados. Mesmo incluindo o fator econômico, este estudo propõe a observar o turismo, o 'Turismo e Eventos' e suas práticas sociais, com um olhar mais humanizado, indo para além das questões economicistas.

Assim, com base nos estudos de Beni e Moesch (2015), do novo SISTUR hologramático, o Turismo será tratado como fenômeno complexo, por meio de uma visão ecossistêmica. Os eventos se relacionando da mesma forma ecossistêmica, para além da setorização turística, numa conjuntura social embasada nos processos de acolhimento e tendo o indivíduo como agente e receptor, ou seja, a base para a construção e o entendimento deste fenômeno. 
Desta forma, o evento é visto nesta investigação como propiciador de experiência turística e local de encontro entre os indivíduos em prol do conhecimento, no qual o acolhimento torna-se fator essencial nos seus processos.

O estudo do conceito de acolhimento, suas categorias principais e complementares, e os saberes dos indivíduos, visa o aprimoramento da qualidade do acolhimento, influenciando as práticas operacionais e organizacionais no 'Turismo e Eventos'.

Portanto, a motivação é refletir sobre os aspectos que envolvem o 'Turismo e Eventos', suas nuances, observando as práticas existentes, partindo da constatação da necessidade de estudos constantes e aprofundados nessa área. Isto, pois se considera que acolher/recepcionar em eventos é uma forma contemporânea de praticar o acolhimento, a hospitalidade tida como genuína, vista como dádiva e a hospitalidade comercial, resultado das relações de comércio, de forma indissociável, ou seja, híbrida; como nos estudos de Gotman apud Camargo (2011) e Avena (2006).

Mesmo identificando a relevância salientada neste estudo, existem poucas pesquisas sobre os campos de investigação Turismo, Eventos e Acolhimento, principalmente interrelacionando-os. Diante disso, a reunião dos assuntos abordados se dá em virtude da complexidade destes campos, da inexistência de pesquisas nesta área e da necessidade de serem estudados como fenômenos complexos para uma efetiva contribuição para a quebra de paradigmas existentes que envolvem o desenvolvimento do indivíduo nas práticas do Turismo, dos Eventos e do Acolhimento.

\section{Turismo em evolução}

O Turismo vem passando por transformações e evoluções conceituais e práticas ao longo de sua trajetória, da mesma forma como ocorre com diversas áreas do conhecimento. Diante disso, numa contribuição à construção do espaço epistemológico no mundo acadêmico do Turismo, este estudo faz distinções quanto à escrita das palavras Turismo, sendo que o Turismo com letra maiúscula faz referência ao campo de conhecimento, enquanto turismo com letra minúscula se refere ao campo de ação, prática, negócio ou produto.

Ao analisar essa trajetória histórica e evolutiva, podem-se observar diversas interpretações que são dadas a esse fenômeno chamado Turismo.

A palavra Turismo tem seu primeiro registro no Pequeno Dicionário de Inglês Oxford em 1800, que o define como: "Teoria e prática de viajar, deslocar-se por prazer. Uso, depredação". Existem registros, na Inglaterra, datados de 1760 , da raiz da palavra turismo, Tour. E, verificando a etimologia da palavra, observa-se também a procedência latina de Tornus e Tornare; dando ideia de giro, viagem ao redor, retornar ao ponto de partida. Outra percepção seria que o Turn britânico cede lugar ao Tour, utilizado nos dias atuais, por influência francesa. Esta raiz etimológica foi utilizada em 
1810, pela primeira vez, em título de obra sobre viagens, no livro de Henry Swinburne, Picturesque Tour Spain. Em 1911, o turismo é conceituado a partir da visão econômica do austríaco Herman Von Schanttenhofen, economista, sendo definido como "os processos econômicos que se manifestam na chegada, na permanência e na saída do turista de um determinado município, estado ou país". Em 1929, considerando a questão do espaço, a "escola berlinesa", a partir de Benscheidt e Glucksmann, conceitua o turismo como "um vencimento do espaço por pessoas que vão para um local no qual não tem residência fixa". Com o passar dos anos, outros autores têm definido o Turismo de diferentes maneiras, porém com semelhanças; sempre abordando a questão do deslocamento e o volume turístico e incluindo aspectos como o consumo de luxo, motivações pessoais, etc.; alguns de forma mais elaborada outros de forma mais simplista (MOESCH, 2000).

A definição considerada como universal/oficial, referenciada internacionalmente, sobre Turismo é aquela elaborada pela Organização Mundial do Turismo (OMT). No entanto, para a academia, esta possui limitações conceituais, pela sua forma simplista. A última revisão conceitual realizada pela OMT foi em 2008 e aponta questões relacionadas a aspectos sociais, culturais e econômicos, além de apontar questões de deslocamentos e prazer direcionado ao lazer como fator motivacional. Assim, salienta Pakman (2014, p. 18):

O turismo é um fenômeno social, cultural e econômico, que envolve o movimento de pessoas para lugares fora do seu local de residência habitual, geralmente por prazer.

Neste trabalho de investigação dar-se-á ênfase às conceituações de Moesch e Beni, pelo fato de serem autores contemporâneos e pesquisadores do fenômeno turístico.

Em seus estudos, Moesch (2000) aborda aspectos importantes que formam o produto turístico, tais como os relacionamentos humanos, objetivos e/ou subjetivos, inclusive de hospitalidade (seja ela qual for, genuína ou comercial), aspectos particulares do meio ambiente, cultura e história, como se pode observar:

O turismo é uma combinação complexa de inter-relacionamentos entre produção e serviços, em cuja composição integram-se uma prática social, com base cultural, com herança histórica, a um meio ambiente diverso, cartografia natural, relações sociais de hospitalidade, troca de informações interculturais. O somatório dessa dinâmica sociocultural gera um fenômeno, recheado de objetividade/subjetividade, consumido por milhões de pessoas, como síntese: o produto turístico (MOESCH, 2000, p. 9).

Ao conceituar Turismo, segundo Beni (2004, p. 37), devem ser mencionadas questões materiais e psicossociais como fatores de satisfação pessoal e social, bem como relações de consumo, equipamentos, meio ambiente, ecologia, a influência da escolha do destino visitado como fator causal de desenvolvimento intelectual e emocional do indivíduo, dentre outros:

Tenho conceituado Turismo como um elaborado e complexo processo de decisão sobre o que visitar, onde, como e a que preço. Nesse processo intervêm inúmeros 
fatores de realização pessoal e social, de natureza motivacional, econômica, cultural, ecológica e científica que ditam a escolha dos destinos, a permanência, os meios de transporte e o alojamento, bem como o objetivo da viagem em si para a fruição tanto material como subjetiva dos conteúdos dos sonhos, desejos, de imaginação projetiva, de enriquecimento existencial histórico-humanístico, profissional e de expansão de negócios. Esse consumo é feito por meio de roteiros interativos espontâneos ou dirigidos, compreendendo a compra de bens e serviços da oferta original e diferencial das atrações e equipamentos a ela agregados em mercados globais com produtos de qualidade e competitivos.

Este mesmo pesquisador (BENI, 2004) alerta para o equívoco de limitar a conceituação de Turismo a meras definições, visto que este fenômeno pode ocorrer em distintos e variados contextos de realidades sociais, da mesma forma que pode ocorrer em campos de estudos diferenciados, como sociologia, antropologia, políticas públicas, economia, acolhimento, eventos; e, por isso, é explicado conforme diferentes correntes de pensamento.

De acordo com os pensamentos de Morin (2000, p. 115 apud BENI e MOESCH, 2015) o não enquadramento definitivo para conceituar o Turismo, bem como as disciplinas, numa necessidade de ecologizar, ou seja, observando em que meio nascem, se desenvolvem e transformam-se; alegando também questões culturais, históricas e aspectos relacionados à hospitalidade, conforme constatamos em suas palavras:

(...) o Turismo não é algo dado. O conceito de 'Turismo' não é dado de uma vez por todas. Encontra-se ligado às culturas, o ato de receber um visitante é enraizado no código da tradição. No código da hospitalidade, é necessário venerar o viajor errante, oferecendo-lhe o que é mais precioso, ou seja, o que é mais íntimo. Tampouco o conceito de hospitalidade cai do céu: é uma construção ligada a uma cultura determinada historicamente.

Após essa reflexão sobre a (r)evolução dos conceitos de Turismo, observa-se, com base nos estudos de Beni e Moesch (2015), que o cerne ou o ponto central do Turismo é de caráter humano, pois são os turistas que se deslocam e não as mercadorias, o que torna mais complexos os esforços para o estudo por meio de uma argumentação sistemática do mesmo, ou seja, o grande desafio para a construção de uma Ciência do Turismo seria a identificação e compreensão do objeto turístico, que quando mal definido tem por consequência a assimilação insuficiente dos conhecimentos adquiridos.

Neste trabalho, com base nos estudos de Beni e Moesch (2015) abordaremos a reconstrução do novo modelo do SISTUR e o paradigma holístico da transdisciplinaridade, ou seja, "aquilo que está ao mesmo tempo entre as disciplinas, através das diferentes disciplinas e além das disciplinas". Considerando também a interdisciplinaridade que é para a elaboração de melhores representações do objeto em estudo, sendo capaz, assim, de passar à ação.

Para exemplificar, Beni e Moesch (2015) apontam o campo das conceituações que toma o turismo como um elaborado e complexo processo de decisão sobre o que visitar, onde, como e a que preço. Intervêm fatores de realização pessoal e social, econômica, cultural, ecológica e científica que ditam a escolha dos destinos, a permanência, os meios de transportes e o alojamento, bem como o 
objetivo da viagem em si, para fruição tanto material como objetiva dos sonhos, desejos, de imaginação projetiva, de enriquecimento existencial histórico-humanístico, profissional, de expansão de negócios. Neste cenário, no estudo em pauta a delimitação se dá na realização e participação em eventos.

Logo, para esses autores, o sistema turístico é um sistema aberto, orgânico e de total interação para atingir equilíbrio entre o todo envolvido. Por isso, não pode ser estudado como uma entidade radicalmente isolada. Daí o seu conteúdo interdisciplinar e transdisciplinar.

Ao estudar o turismo como realidade humana o compreendemos como uma amálgama na qual tempo, espaço, diversão, economia, tecnologia, imaginário, comunicação, diversão, ideologia, hospitalidade são categorias fundantes de um fenômeno social contemporâneo, em que o protagonista é o sujeito, seja como produtor ou consumidor dessa prática social. Não é negada a contingência material do turismo em sua expressão econômica, mas ela ocorre historicamente, em espaços e tempos diferenciados, cultural e tecnologicamente construídos, a ser irrigado com o desejo de um sujeito biológico, nômade em sua essência. Sujeito objetivado, fundamental para a compreensão do fenômeno turístico como prática social, e subjetivado em ideologias, imaginários e necessidade de diversão e encontro, na busca do elo perdido entre prosa e poesia. (BENI e MOESCH, 2015).

Gradativamente verifica-se que há uma evolução conceitual para definir o turismo conforme seus estudos vão se aprofundando, como afirma Moesch:

O turismo constitui-se num fenômeno sociocultural de valor simbólico aos sujeitos que o praticam. $O$ sujeito turístico consome o turismo, por meio de um processo tribal, de comunhão, de re-ligação, de testemunho, em um espaço e tempo tanto real como virtual, desde que possível de convivência, de presenteísmo. O valor simbólico, perpassado pela comunicação táctil deste fenômeno, reproduz-se, ideologicamente, quando os turistas comungam de sentimentos reproduzidos pela diversão, e quando há a possibilidade de materialização do imaginário, por vezes individual, em societal (MOESCH, 2000, p. 134).

O avanço do fenômeno turístico deve ser visto para além de seu valor economicista, para que haja uma expansão da sua prática epistemológica. O meio acadêmico tem condições de investir no saber-fazer e contribuir para o desenvolvimento adequado do Turismo e, assim, livrar-se do fazersaber (MOESH, 2000) empírico que empobrece o mercado e que vem pautando as práticas do turismo no Brasil.

\section{'Turismo e Eventos': eventos como lugar de encontro e acolhimento}

Neste estudo o termo turismo de eventos, que visa o evento apenas como impulsionador de fluxo turístico será substituído por 'Turismo e Eventos' numa iniciativa acadêmica de olhar o evento como uma experiência turística imbuída de acolhimento, um lugar de encontro nos processos do Turismo ecossistêmico, como fenômeno social complexo.

No 'Turismo e Eventos' a necessidade de desenvolver o saber-fazer de forma melhor fundamentada teoricamente é latente. O principal objetivo de um evento é difundir conhecimento e estabelecer relações sociais entre os indivíduos, locais ou turistas, e também é necessário o 
conhecimento para a organização e realização do evento. Todo esforço no sentido da criação ou desenvolvimento do conceito do acolhimento e da categoria da hospitalidade, no segmento de eventos, necessita do envolvimento das comunidades receptoras e dos prestadores de serviços do evento.

Para Melo Neto, (2000) um evento pode ser considerado um elemento, um agente de transformação social, de conscientização, educação, mobilização, fator de desenvolvimento ou impulsionador do turismo. Uma forma de alavancagem de negócios profissional e pessoal, pois sem eventos não se atrai público, não há venda, não há promoções de marcas ou cidades. Os eventos criam, recriam, inovam e reinventam acontecimentos; esse princípio mostra a importância desse setor para a economia, o desenvolvimento do mercado e do indivíduo.

No entanto, criar eventos não é tarefa fácil, pois é preciso uma gama enorme de profissionalização. É preciso um saber-fazer específico, construir, executar e aprimorar saberes, usando a criatividade para inovar a cada dia, com novas formas de comunicação, temas inovadores, desbravando caminhos em busca do conhecimento. E este, por sua vez, não é estático e evolui juntamente com a história da humanidade.

Matias (2003, p. 251) define o 'Turismo e Eventos' de forma mais abrangente, levando em consideração o fator principal dos eventos, a difusão de conhecimentos:

Turismo de Eventos é o conjunto de atividades exercidas por pessoas que viajam a fim de participar dos diversos tipos de eventos que visam ao estudo de alternativas, de dimensionamento ou de interesses de determinada categoria profissional, associação, clube, crença religiosa, corrente científica ou outra organização com objetivos nos campos científicos, técnicos e religiosos para atingir objetivos profissional-cultural, técnico-operacional, de aperfeiçoamento setorial ou de atualização (MATIAS, 2003, p. 251).

Outro aspecto complementar relacionado aos eventos é seu aspecto singular mencionado por Goldblatt apud Watt (2004, p. 15). Este afirma que "um evento especial reconhece um momento único no tempo, com cerimônia e ritual, para satisfazer necessidades específicas".

Por conseguinte, como não poderia deixar de ser, o elemento humano é a razão de ser de todo evento. Nesse contexto, Nakane (2013) salienta que o fator primordial dos eventos é o agrupamento de pessoas reunidas em certo local, data, horário, sintonizadas com interesses em comum, e isso se dá a partir de bastante planejamento detalhado desse acontecimento.

Esta autora também traz à reflexão a ampla e complexa conceituação de eventos, pois não se deve prender a uma única definição para compreender esse universo. Da mesma forma que, considerando essa total diversidade, há a possibilidade de mensurar mais de sessenta tipos, que podem apresentar diferenças sutis ou se enquadrar em mais de uma classificação. No entanto, esse entendimento torna-se vital para o bom planejamento e desenrolar de um evento. 
Para que se realizem os eventos é necessária uma gama de fatores interligados e integrados entre si, pois são diversos serviços se unindo em prol de um mesmo objetivo. Como recursos humanos qualificados, tecnologias adequadas e disponíveis, comunicação eficaz que atinja o públicoalvo, capacidade técnica e operacional, os atrativos turísticos naturais ou artificiais da cidade sede do evento e a localização desta cidade geram vantagens competitivas para a realização bem sucedida do evento. Para isso, é preciso investir na qualidade e no grau de especialização dos serviços. (CANTON, 2002).

Na visão da autora citada acima, agregar valor aos serviços, aprender, reinventar-se, investir em conhecimentos, pois o conhecimento é a base para ser criativo e para a inovação, para gerar novos processos, novos meios para o desenvolvimento da sociedade. Nesse cenário, para entender bem o poder do evento bem realizado e seus impactos sociais e econômicos, é necessário visualizá-lo como instrumento de diferenciação e apelo, com poder integrador e catalisador de demandas.

Estabelecer melhorias nos eventos por meio da inovação e criatividade, caminhando e evoluindo conjuntamente com as aspirações ou necessidades do mercado, tendo o indivíduo como protagonista do processo, torna-se fator primordial, pois o evento se transforma num espaço de encontro, num lugar de acolhimento. Para tanto, há um constante pensar no outro, considerando a alteridade e o exercício contínuo do acolhimento por meio do seu conceito e de suas categorias principais e complementares. Por isso, estudamos a relação Turismo-Eventos-Acolhimento, cujo cerne desta relação é o indivíduo enquanto ator deste processo ou deste fenômeno social, visto que o evento se propicia a ser um espaço de acolhimento.

\section{O Acolhimento}

Estudar a hospitalidade torna-se um desafio por sua diversidade de abordagens e seus conceitos podem ser incipientes, tornando o entendimento deste vasto campo de estudo insuficiente para o entendimento abrangente deste fenômeno, bem como de sua aplicabilidade e historicidade.

A comercialização da hospitalidade e o acolhimento mercantilizado não podem depreciar a genuinidade destes conceitos, pois na atualidade é difícil separá-los. Grinover (2007, p. 59) salienta a constante intenção de harmonizar o genuíno com o comercial, muitas vezes com dificuldades e barreiras para concretizar esta harmonia, mas sugere como estratégia a utilização do "acolhimentoestado de espírito das relações humanas; acolhimento-atmosfera ambiental, o acolhimento-atenção pelo outro, o acolhimento-oxigênio do turista". Este autor conceitua acolhimento como

O conjunto dos comportamentos, das políticas e das técnicas utilizadas para ter um bom êxito na aproximação do turista e dos hóspedes, no sentido de uma relação humana de qualidade, com o objetivo de satisfazer sua curiosidade, suas necessidades, seus gostos e aspirações, e na perspectiva de desenvolver e estimular o conhecimento, a tolerância e a compreensão entre os seres humanos. Hoje, substância principal do turismo e seu único fator humano, é o acolhimento 
remanescência da antiga hospitalidade adaptada à sociedade moderna, que inspira e condiciona a concepção dos equipamentos, dos serviços, da animação e da atmosfera de qualquer atividade turística. (GRINOVER, 2007, p. 60).

Kops (2014) faz reflexões sobre a hospitalidade como um paradigma que pode mudar as culturas sociais e ressalta questões da educação para a hospitalidade.

Para esta autora os saberes são fatores positivos para as competências organizacionais, sendo reproduzidos pelos indivíduos e reestruturando a complexidade social. Em suas palavras, "a hospitalidade, como paradigma, é um referencial transversal capaz de influenciar os saberes e fazeres dos colaboradores com a formação de atitude hospitaleira". (KOPS, 2014, p. 195).

Avena (2006) afirma que existem poucos estudos sobre o acolhimento no Brasil e que há uma tendência em considerar o acolhimento sinônimo de hospitalidade. Porém, em seus estudos, estabelece uma distinção entre os dois termos e ressalta que a hospitalidade está contida no acolhimento.

Este autor também faz uma significativa reflexão sobre o papel do indivíduo nos processos de acolhimento. Ressalta a importância de que quem acolhe observe o Outro com empatia, ou seja, o trate como gostaria de ser tratado e crie no ambiente de acolhimento, seja em qualquer equipamento turístico ou evento, condições para que se sintam realmente acolhidos.

Quando aborda questões sobre os lugares de acolhimento, Avena (2006) traz a reflexão sobre a primeira impressão que o indivíduo cria deste lugar de acolhimento, que pode ser boa ou má, e depende da qualidade do serviço prestado e do acolhimento ofertado. Podem ser considerados como lugares de acolhimento: as cidades, eventos, hotéis, equipamentos turísticos diversos, etc.

Como o indivíduo também pode ter influência nesta primeira impressão do lugar de acolhimento percebeu-se a relevância de investigar a formação e os saberes dos trabalhadores para que, possivelmente, possa ser direcionada aos conceitos do acolhimento.

Para o embasamento teórico deste aspecto sobre os saberes amparou-se nos estudos de Freire (1996), Lyotard (2011) e Perrenoud (2001), visando a junção pertinente e propositiva de seus ensinamentos, pois, acredita-se na importância da discussão e aplicação dos saberes do indivíduo em sua conduta de trabalho nos eventos, seja ele empírico ou acadêmico e sob vertentes variadas.

\section{O saber-fazer dos indivíduos}

Freire (1996) relata a importância da crítica, de pensar a prática criticamente e ter uma aproximação epistemológica, dando mais inteligência à prática, o que pode tornar o indivíduo mais aberto à mudança, capaz de mudar-se e promover-se, transformando a "curiosidade ingênua em curiosidade epistemológica". Ou seja, a questão do saber-fazer é uma prática criticada, prática refletida com esses elementos. 
É pensando criticamente a prática de (hoje) ou de ontem que se pode melhorar a próxima prática. $O$ próprio discurso teórico, necessário à reflexão crítica, tem de ser de tal modo concreto que quase se confunda com a prática. (FREIRE, 1996, p. 18).

Para Lyotard (2011, p. 36) ao termo saber "misturam-se ideias de saber-fazer, saber-viver, saber-escutar, etc.". O saber é "aquilo que torna alguém capaz de proferir bons enunciados denotativos, prescritivos, avaliativos...". O saber permite boas performances de discursos, como conhecer, decidir, avaliar, transformar. E uma de suas principais características é a formação de competências no indivíduo, que "é a forma única encarnada em um sujeito constituído pelas diversas espécies de competências que o compõem".

De acordo com Perrenoud (2001) existem dois tipos de saberes: os eruditos, que são os saberes científicos, da academia e, também, os oriundos de escolas, instituições, centros de pesquisas aplicadas; e os saberes de experiência, ou de senso comum, que são construídos graças à experiência, e não à formação. Este autor também relata a importância de um não se opor ao outro e se complementarem em momentos e campos específicos, sem se eliminarem e sim criando uma ponte entre os dois saberes.

Por conseguinte, é importante compreender de onde vêm os saberes dos profissionais e como se reúnem os saberes de diversas fontes. E, a grande questão da disseminação dos conhecimentos é a compreensão de como os indivíduos utilizam os saberes em determinadas situações; por isso, nesta reflexão, Perrenoud (2001) acredita que todos os saberes são de ação, para agir corretamente perante as situações.

Neste contexto, Lyotard (2011) menciona o papel das universidades junto aos saberes teóricos e práticos da comunidade e do indivíduo, como uma fonte de saber, além de abordar em seus estudos aspectos sobre o poder dos saberes e como isso pode influenciar no cotidiano das sociedades.

\section{Metodologia}

Neste artigo constam partes da pesquisa de campo oriunda do trabalho de dissertação e para a obtenção destes dados foi utilizado como método o Multirrefencial.

Para Ardoino (1998), a multirreferencialidade propõe uma leitura plural de seus objetos, tanto práticos como teóricos, sob diferentes pontos de vistas, o que implica em visões específicas, linguagem apropriada, em sistemas considerados heterogêneos. Preocupa-se em tornar mais legíveis os fenômenos sociais, a partir de leituras plurais, em que as perspectivas multidisciplinares observam o objeto de estudo sob outro ângulo, assumindo rupturas epistemológicas.

Já para Borba (2001) a multirreferencialidade é construída por meio de uma bricolagem, uma atualização, articulação e rearticulação de conceitos e dispositivos, num processo de reificação de 
todo procedimento que tenha por objetivo um discurso pleno e perfeito; até mesmo negando esse discurso pleno e perfeito; observando diferentes aspectos e suas nuanças, bem como os não-ditos contextuais.

A Bricolagem, para o autor mencionado acima, é a arte da articulação de saberes. E enfatiza, que é articulação e não fusão ou confusão. É um trabalho artesanal da inteligência face às coisas e situações. Borba (2001) ressalta que esta perspectiva exige do pesquisador a capacidade de criar sentido para suas ações no correr do fazer, ou seja, que ele se autorize, faça-se sujeito e, para isso, é preciso ir além do que é frequente, sair da alienação proposta ou imposta cotidianamente.

Lapassade (1998) afirma que a bricolagem é parte essencial da multirreferencialidade nas ciências sociais, e para praticar esse método o pesquisador deve aprender a bricolar.

Diante destes estudos e reflexões de diversos autores, observou-se a necessidade metodológica de abordar os estudos sobre o Brico-método.

O Brico-método teve origem nos estudos de Avena (2008) em sua tese que perpassa pelos campos de estudos do turismo, das viagens e do acolhimento. O termo foi criado a partir da necessidade de denominar uma proposta de abordagem metodológica que envolvesse os estudos da complexidade de Morin, a multirreferencialidade de Ardoino e a Bricolagem metodológica de Lapassade.

Morin é considerado referência quando se fala em complexidade, possui diversas obras com vários volumes que abordam estudos sobre método, levando sempre em consideração o sujeito complexo e suas referências. E a partir desta reflexão macro da complexidade, Ardoino, que é contemporâneo a Morin, desenvolveu os conceitos de multirreferencialidade.

Por possuir uma formação educacional também multirreferencial, englobando áreas como a psicologia, educação, direito dentre outras, percebeu que a abordagem tradicional não atendia às necessidades do desenvolvimento do sujeito por serem abordagens fechadas, ou seja, as técnicas educacionais não se adequavam à complexidade dos sujeitos; por isso, amparado na complexidade de Morin, Ardoino desenvolve seus estudos para uma perspectiva metodológica multirreferencial, uma perspectiva aberta.

Quando se trata da bricolagem metodológica, o patchwork de ideias, a âncora autoral é Lapassade.

Após estudar estas vertentes e utilizá-las em sua tese, Avena (2008) percebeu a relevância de criar um termo que aglutinasse as perspectivas destes três autores citados, então, cria o termo Bricométodo.

Portanto, neste trabalho, utilizam-se as premissas do Brico-método e sua interface nos campos de estudo do Turismo, Eventos e Acolhimento. Esta construção teórica respalda o caminho 
metodológico escolhido para análise do trabalho. Bem como, numa abordagem qualitativa, um estudo de caso de um evento técnico-científico, observação participante, aplicação de questionários e entrevistas com atores envolvidos no evento.

\section{Alguns achados da pesquisa de campo relacionados aos campos de investigação Turismo, Eventos}

\section{e Acolhimento}

Os autores envolvidos no evento pesquisado são os organizadores, o promotor, participantes e trabalhadores recepcionistas.

Em se tratando do campo de investigação Turismo, com a análise dos dados coletados por meio dos instrumentos de pesquisa, percebeu-se que, de uma forma geral, os pesquisados não possuem a visão do turismo ecossistêmico mencionada neste estudo e sim, um olhar economicista. Desta forma, para eles, o evento tem relevância no sentido de desenvolver o consumo nos equipamentos turísticos relacionados, como hotéis, restaurantes e demais atividades relativas ao comércio; de uma forma sucinta e superficial, fazem a relação do turismo e eventos com a aquisição de conhecimentos e o envolvimento de pessoas neste processo.

O perfil dos pesquisados se resume a Trabalhadores que tem como profissão ser recepcionista de eventos com o intuito de aquisição ou complemento de renda mensal, predominância do gênero feminino, jovens, renda abaixo de três salários mínimos por mês, possui ensino médio ou a maioria cursou ou cursa ensino superior fora da área de turismo ou eventos. Percebe-se que se intitulam profissionais desta área, porém há uma lacuna quanto à qualificação específica. Apesar de muitos apontarem a necessidade de qualificação.

O campo de investigação Eventos foi idealizado a partir de conceitos que abordam o evento como momento único de encontro entre as pessoas, com o objetivo de troca de conhecimento, com a necessidade de inovação e envolvimento de diversos setores.

Estudos científicos nesta área ainda são poucos, há diferentes interpretações e abordagens que podem ser complementares e permanece o desafio acadêmico de aprofundar as pesquisas e transpô-las à prática das relações.

Os pesquisados, por falta de conhecimento fazem relações equivocadas quanto à tipologia dos eventos, fato que pode influenciar no pré, trans e pós evento. E apontam insatisfações relacionadas a gestão de processos do evento. Todos eles apontaram necessidade de qualificação profissional, e os trabalhadores acreditam nisso para ser um bom profissional da área de eventos, podendo assim, acolher o participante.

Já no campo de investigação Acolhimento os atores envolvidos no evento apresentam preocupação superficial quanto à importância e aplicabilidade do acolhimento. A falta de 
conhecimentos específicos os impede de aplicar as categorias de acolhimento, portanto as ações utilizadas no evento visando as categorias do acolhimento são insipientes.

\section{Considerações finais}

O processo comercial do acolhimento, quando bem executado, envolvendo a ética e a dedicação tem a capacidade de ofertar aos atores uma relação social de forma apaixonante. Para tanto, acredita-se na educação e qualificação para o acolhimento. Uma tentativa de mudar as relações humanas pela alteridade; pois, se o indivíduo olhar para o outro e se inserir nas condutas embasadas na alteridade, este pode se tornar um indivíduo acolhedor. Exercitando a sensibilidade social para o trato com o outro, independente das nuances dos contextos culturais e não excluindo as relações comerciais, mas evitando conflitos.

Assim, complementando as análises, aponta-se a necessidade de reflexão sobre o aprofundamento dos estudos específicos sobre eventos e os assuntos que contêm e que estão contidos nesta prática, como o Turismo e os princípios do acolhimento. Além da reflexão sobre o sujeito como ator e receptor dos processos de acolhimento, ou seja, o ponto crucial de desenvolvimento seria este sujeito como ser multirreferencial, inserido nas ações sociais do evento como lugar de encontro.

Por conseguinte, os locais de acolhimento sendo idealizados sobre os preceitos propostos por Avena (2006) fazem com que a pessoa que chegue ao lugar estranho para participar do evento se sinta integrada àquele ambiente e ao processo em si, ou seja, se sinta realmente acolhido, bem recepcionado e bem atendido. Tendo uma imagem propositiva do evento. Sob outra perspectiva, este local de acolhimento também pode ser idealizado como local de aprendizagem ao indivíduo que esteja trabalhando, numa oportunidade de colocar em prática seus conhecimentos acadêmicos e desenvolver sua experiência prática ou servir de incentivo para o aperfeiçoamento contínuo do trabalhador.

Numa reflexão teórica sobre a prática, em busca da transformação da práxis numa prática refletida, esta pesquisa sugere uma contribuição social a partir de um diálogo com as instituições ou associações que estão na área de eventos, como a $A B E O C$, visando a quebra de paradigmas existentes nestas práticas, muitas vezes empíricas, ou seja, a utilização dos conceitos acadêmicos para que altere no sentido de trazer melhorias às condutas sociais existentes nos eventos, nos relacionamentos e técnicas profissionais e nos processos de humanização.

A sociedade mundial passa por período conturbado social e político, em que o outro precisa ser tratado de forma mais humana, respeitando sua singularidade cultural e ética. Boff $(2005$, p. 197) faz reflexões sobre este sentido e ressalvas quanto à consciência pela hospitalidade: "É importante que se crie o mais rápido possível a consciência da urgência da hospitalidade". Neste contexto, 
aponta-se para a necessidade de reflexões sobre a qualificação pessoal visando à hospitalidade e, de forma minuciosa, visando o conceito de acolhimento estudado neste trabalho. Como uma tentativa, talvez utópica, de relações ternas, solidárias, nos processos comerciais dos eventos e das práticas do turismo.

Por fim, essa pesquisa pode servir de base para estimular os profissionais envolvidos com os processos de planejamento e organização de eventos a refletirem sobre suas práticas, a busca por conhecimento específico, a necessidade de aperfeiçoamento contínuo e aos processos de humanização dos eventos.

Da mesma forma, pode servir para os docentes refletirem sobre os conteúdos dos cursos existentes que englobem o 'Turismo e Eventos' a fim de realizar a inserção dos conceitos de acolhimento e voltar o olhar para o agente acolhedor e o sujeito acolhido, ou seja, o trabalhador e o participante do evento, visando sempre o acolher, o receber bem. Portanto, uma reflexão perante as estruturas curriculares dos cursos, o que tende a repercutir nas ações práticas.

Perante tais reflexões: Encontre-se! Recrie! Acolha!

\section{REFERÊNCIAS}

ARDOINO, Jacques. Abordagem multirreferencial (plural) das situações educativas e formativas. In: BARBOSA, Joaquim Gonçalves (Org.). Multirreferencialidade nas ciências e na educação. São Carlos: EdUFSCar, 1998.

AVENA, Biagio M. Por uma pedagogia da viagem do turismo e acolhimento: itinerário pelos significados e contribuições das viagens à (trans)formação de si. Tese (Doutorado em Educação). Faculdade de Educação da Universidade Federal da Bahia, Bahia, 2008.

AVENA, Biagio M. Turismo, educação e acolhimento: um novo olhar. São Paulo: Roca, 2006.

BENI, Mário Carlos. Análise estrutural do turismo. 10ạ ed. atualizada. São Paulo: Senac, 2004.

BENI, Mário Carlos; MOESCH, Marustchka M. Do Discurso sobre a Ciência do Turismo para a Ciência do Turismo. Artigo apresentado no XII Seminário Anual da Associação Nacional de Pesquisa Pós-Graduação em Turismo: 2015.

BOFF, Leonardo. Virtudes para um mundo possível. Hospitalidade: direitos e deveres de todos. Vol.I. Petrópolis, RJ: Vozes, 2005.

BORBA, Sérgio da Costa. Multirreferencialidade na formação do professor-pesquisador: da conformidade à complexidade. 2ª edição. Maceió: Edufal, 2001.

CAMARGO, Luiz Octávio de L. O estudo da hospitalidade. In: MONTANDON, Alain (Org.). O livro da Hospitalidade: acolhida do estrangeiro na história e nas culturas. São Paulo: Senac, 2011.

CANTON, Marisa. Os eventos no contexto da hospitalidade - um produto e um serviço diferencial. In: DIAS, Célia Maria de Moraes (Org.). Hospitalidade: reflexões e perspectiva. Barueri: Manole, 2002. 
FREIRE, Paulo. Pedagogia da autonomia: saberes necessários à prática educativa. São Paulo: Paz e Terra, 1996.

GRINOVER, Lucio. A hospitalidade, a cidade e o turismo. São Paulo: Aleph, 2007.

LAPASSADE, Georges. Da multirreferencialidade como "Bricolagem". In: BARBOSA, Joaquim Gonçalves (Org.). Multirreferencialidade nas ciências e na educação. São Carlos: EdUFSCar, 1998.

LYOTARD, Jean-François. A condição pós-moderna. 14 ed. Rio de Janeiro: José Olympio, 2011.

MATIAS, Marlene. Turismo de Eventos: relação entre sociedade e espaços de eventos. In: BAHL, Miguel (Org.). Turismo: enfoques teóricos e práticos. Organizador: Miguel Bahl. São Paulo: Roca, 2003.

MELO NETO, Francisco Paulo de. Criatividade em eventos. São Paulo: Contexto, 2000.

MOESCH, M. A produção do saber turístico. São Paulo: Contexto, 2000.

NAKANE, Andrea. Segurança em eventos: não dá pra ficar sem!. São Paulo: Aleph, 2013.

PAKMAN, Elbio Troccoli. Sobre as definições de Turismo da OMT: Uma contribuição à História do

Pensamento Turístico. Artigo apresentado no

XI Seminário Anual da Associação Nacional de Pesquisa Pós-Graduação em Turismo: 2014.

PERRENOUD, Philippe. Ensinar: agir na urgência, decidir na incerteza. $2^{\circ}$ ed. Porto Alegre: Artmed Editora, 2001.

WATT, David C. Gestão de eventos em lazer e turismo. Porto Alegre: Bookman, 2004. 